\title{
INTEREST ARBITRATION, OUTCOMES, AND THE INCENTIVE TO BARGAIN
}

\author{
HENRY S. FARBER and HARRY C. KATZ
}

$\mathrm{D}_{\mathrm{o}}^{\mathrm{s}}$ ISPUTES between unions and employers over the terms of employment have traditionally been settled through a bargaining process in which the strike has been the weapon of last resort. The threat of a strikewhich imposes costs on both parties-acts as an incentive for the parties to reach a bargained settlement; more formally, the strike threat creates a "contract zone," or a range of potential settlements that both parties consider preferable to a strike. The recent increase in public sector unionization has sparked efforts to devise procedures for settling labor disputes in that sector without resort to the strike. Binding third party intervention in the form of interest arbitration is an alternative that has been utilized in a number of jurisdictions. ${ }^{1}$

This study develops a model of bargaining that demonstrates that an interest arbitration procedure will encourage negotiated settlements to the extent that risk aversion dominates the preferences of the parties and there is uncertainty regarding the arbitrator's behavior. The authors conclude that it is likely that risk aversion does dominate preferences, but the evidence is not conclusive. They also argue that uncertainty may be reduced over time for various reasons, leading to increased use of arbitration and a convergence between the terms of negotiated and arbitrated agreements.

Henry S. Farber and Harry C. Katz are Assistant Professors of Economics at Massachusetts Institute of Technology. They acknowledge the helpful comments of Peter Diamond, Ronald Ehrenberg, Peter Feuille, David Lipsky, Charles Myers, Melvin Reder, and Robert Solow.-EDITOR

\footnotetext{
' States utilizing binding arbitration procedures in the public sector include Alaska, Connecticut, Iowa, Massachusetts, Michigan, Minnesota, Nebraska, Nevada, New York, Oregon, Pennsylvania, Rhode Island,
}

Two criteria have frequently been used to evaluate interest arbitration and other dispute settlement procedures. The first is the frequency with which it is necessary to employ the procedure. It is commonly thought that a good procedure is one that is seldom used and that provides an incentive for the parties to reach a negotiated settlement. ${ }^{2}$ The rationale for this is that there are unique aspects to every collective bargaining relationship, which only the parties themselves can fully appreciate. As with the strike, the presence of an arbitration procedure theoretically provides the parties with an incentive to reach a negotiated settlement by creating a contract zone within which any settlement is considered by both parties to be preferable to arbitration. It will be argued here that the ability of an arbitration procedure to create such a contract zone depends in large measure on the risk preferences of the parties as well as on their uncertainty concerning the arbitrator's decision.

A second criterion often used to evaluate dispute settlement procedures is the extent to which the presence of the procedure creates an environment in which both the bargained and the arbitrated settlements do not differ significantly from those the parties

\footnotetext{
South Dakota, Washington, Wisconsin, and Wyoming. See U.S. Department of Labor, Summary of Public Sector Labor Relations Policies (Washington, D.C.: Labor-Management Services Administration, 1976).

${ }^{2}$ For example, see George W. Taylor, Government Regulation of Industrial Relations (Englewood Cliffs, N.J.: Prentice Hall, 1948), p. 1.
} 
would have reached in an environment that did not include the procedure. The implication is that a good procedure is one whose presence biases neither the negotiated nor the arbitrated settlements. It is contended here that the dispute settlement mechanism, be it a strike or a legislatively mandated procedure such as arbitration, defines the environment within which bargaining takes place. Consequently, any analysis of the impact of dispute settlement procedures must recognize that the mere presence of the procedure directly affects negotiated as well as arbitrated outcomes.

This paper explores these issues by first developing a model of bargaining in the presence of an arbitration procedure and examining the implications of that model for the usage rates of the arbitration procedure. We will then develop another bargaining model that enables us to investigate the potential bias in negotiated outcomes introduced by the arbitration procedure.

\section{The Analytical Framework}

Strikes create a contract zone of potential settlements considered superior to the strike outcome by both parties by imposing the direct costs of forgone income on both parties. Each party is willing to sacrifice some potential gains in order not to bear the costs of a strike. ${ }^{3}$

Assuming that arbitration does not impose any direct costs on the parties, it must create (define) a contract zone through a mechanism that is fundamentally different from that of the strike. ${ }^{4}$ The major source of arbitration leverage is derived from the uncertainty of the parties regarding the behavior of the arbitrator: the parties are willing to give up some of the expected gains from an arbitrated settlement in order to avoid the attendant uncertainty. It is our contention that this phenomenon depends

\footnotetext{
"Hicks argues that ". . most strikes are doubtless the result of faulty negotiation." See John R. Hicks, The Theory of Wages (London: MacMillan Press, 1963), p. 146. In other words, the existence of a contract zone should allow the parties to reach agreement without a strike in most cases.

'Of course, positive direct costs of arbitration (such as time and attorney's fees) will tend to create a contract zone in a manner analogous to a strike.
}

crucially on the risk preferences of the parties.

The model developed below utilizes the analytical construct of maximization of expected utility by agents in the presence of uncertainty. This framework was introduced by Von Neumann and Morgenstern and has become a part of standard economic analysis. ${ }^{5}$ The definition of an uncertain situation used here is that of one in which the precise outcome is unknown but the parties form well-defined expectations of the probability distribution of the various possible outcomes. ${ }^{6}$

A number of assumptions concerning the bargaining process, the utility functions of the parties, and the behavior of the arbitrator are made. First, it is assumed that there is a homogeneous "pie" of fixed size and that the parties bargain over the division of the pie. Let the pie be of size one so that the share of each party can be represented by a number between zero and one. Let $y_{a}$ represent the share of party $a$ and $z_{b}=1-y_{a}$ represent the share of party $b$.

Second, let each party have a utility function: $^{7}$

$$
U_{a}=U_{a}\left(y_{a}\right)
$$

and

$$
U_{b}=U_{b}\left(z_{b}\right) .
$$

Further, let $U_{a}(0)=0, U_{b}(0)=0, U_{a}(1)=1$, and $U_{b}(1)=1 .^{8}$ Assuming positive marginal

${ }^{5}$ For a more detailed exposition of this framework, see Duncan R. Luce and Howard Raiffa, Games and Decisions (New York: John Wiley and Sons, 1957).

${ }^{6}$ This contrasts with a framework that draws a distinction between situations in which the agents have knowledge of a probability distribution of outcomes (called risk) and situations in which the probabilities of outcomes are completely unknown or are not meaningful (called uncertainty). See James G. March and Herbert A. Simon, Organizations (New York: John Wiley and Sons, 1959), pp. 196-42.

The difficult problem of aggregating individual preferences into a consistent group preference ordering is beyond the scope of this study. See Kenneth J. Arrow, "A Difficulty in the Concept of Social Welfare," Journal of Political Economy, Vol. 58, No. 4 (August 1950), pp. $328-46$. An analysis of the problem specific to unions is contained in Wallace N. Atherton, Theory of Union Bargaining Goals (Princeton, N.J.: Princeton University Press, 1973).

${ }^{8}$ These assumptions involve linear transformation of an arbitrary utility index. Under certain general 
utilities, it is clear that the utilities of the parties are in direct opposition to one another and that the gain of one party is the loss of the other.

Parameterizations of the utility functions that satisfy the above constraints are

$$
U_{a}=\frac{1-e^{y_{a} c_{a}}}{1-e^{c_{a}}}
$$

and

$$
U_{b}=\frac{1-e^{z_{b} c_{b}}}{1-e^{c_{b}}} \text {. }
$$

These are convenient functional forms because, regardless of the values of $c_{a}$ or $c_{b}$, they always exhibit positive marginal utility and because the risk preferences of the parties are completely determined by $c_{a}$ and $c_{b}$. Party $a$ is risk averse, risk neutral, or risk loving as $c_{a}$ is, respectively, less than, equal to, or greater than zero. ${ }^{9}$ The analogous conditions determine the risk preferences of party $b$.

Assume further that the arbitrator's role is to choose a $y_{a A}$ that represents the arbitrator's award to party $a$. This, of course, determines $b$ 's share $\left(z_{b A}=\left(1-y_{a A}\right)\right)$. Neither party knows with certainty what the arbitrated settlement will be. However, it is reasonable to assume that each party forms expectations about the arbitrator's decision. Let these expectations be summarized by the normal distributions

$$
\begin{aligned}
& y_{a A} \sim N\left(y_{a F}, \quad \sigma_{a}^{2}\right) \\
& z_{b A} \sim N\left(z_{b F}, \sigma_{b}^{2}\right)
\end{aligned}
$$

where $y_{a F}$ and $z_{b F}$ are the arbitration awards expected by each party, should the proced-

conditions, such a transformation does not alter the risk behavior of the parties. See Luce and Raiffa, Games and Decisions, pp. 12-38.

${ }^{9}$ Absolute risk aversion $(A R A)$ of party $a$ is defined as $\frac{-U_{a}^{\prime \prime}}{U_{a}^{\prime}}=-c_{a} . U_{a}$ and $U_{b}$ are undefined for $c_{a}$ and $c_{b}$ equal to zero respectively, but by L'Hospital's rule $\lim U_{a}\left(y_{a}\right)=y_{a}$ which is a linear and hence a risk $c_{a} \rightarrow 0$

neutral utility function. The analogous results hold for party $b$. ure be utilized. These may be determined by some notion of a "fair" settlement, and they may or may not be equal. ${ }^{10} \sigma_{a}^{2}$ and $\sigma_{\mathrm{b}}$ represent the expected variances of the awards around $y_{a F}$ and $z_{b F}$ and hence are a measure of the uncertainty involved in the use of the arbitration procedure perceived by each party. ${ }^{11}$

Given these prior distributions, each party calculates the expected utility to them of using the arbitration procedure:

$E\left(U_{a}\right)=\int_{-\infty}^{\infty} \frac{1-e^{y_{a} c_{a}}}{1-e^{c_{a}}} f\left(y_{a} ; y_{a F}, \sigma_{a}^{2}\right) d y_{a}$

and

$E\left(U_{b}\right)=\int_{-\infty}^{\infty} \frac{1-e^{z_{b}^{c} b}}{1-e^{c b}} f\left(z_{b} ; z_{b F}, \sigma_{b}^{2}\right) d z_{b}$

where $f\left(y_{a} ; y_{a F}, \sigma_{a}^{2}\right)$ and $f\left(z_{b} ; z_{b F}, \sigma_{b}^{2}\right)$ are normal probability density functions defined in Equations 5 and 6 . Using the definition of a moment-generating function for a normal density, these integrals have the analytical solutions,

$$
E\left(U_{a}\right)=\frac{1-e^{\left(c_{a} y_{a F}+\frac{1}{2} \sigma_{a}^{2} c_{a}^{2}\right)}}{1-e^{c_{a}}}
$$

and

$$
E\left(U_{b}\right)=\frac{1-e^{\left(c_{b}^{z} b F+\frac{1}{2} \sigma_{b}^{2} c_{b}^{2}\right)}}{1-e^{c_{b}}} .
$$

These expected utilities are combined with the utility functions in order to solve for the certainty equivalent shares $\left(y_{a s}\right.$ and $\left.z_{b s}\right)$,

\footnotetext{
${ }^{10}$ Equality is not $y_{a F}=z_{b F}$, but $y_{a F}=1-z_{b F}$, or identical expectations.

"The arbitrator's award must be constrained to the unit interval while the normal distribution implies a nonzero probability of an award outside the unit interval. It is assumed here that $\sigma_{a}^{2}$ and $\sigma_{b}^{2}$ are sufficiently small so that the probabilities of an award outside the unit interval are insignificant. If this is true, use of an unbounded distribution does not seriously alter the results.
} 
which are the $y_{a}$ and $z_{b}$ that, received with certainty, would yield the same utilities as those expected from arbitration:

$$
U_{a s}=\frac{1-e^{y_{a s^{c} a}}}{1-e^{c_{a}}}
$$

and

$$
U_{b s}=\frac{1-e^{z} b s^{c} b}{1-e^{c b}}
$$

Solving $U_{a s}=E\left(U_{a}\right)$ and $U_{b s}=E\left(U_{b}\right)$ from Equation 9 through 12 for $y_{a s}$ and $z_{b s}$ yields

$$
y_{a s}=y_{a F}+\frac{1}{2} \sigma_{a}^{2} c_{a}
$$

and

$$
z_{b s}=z_{b F}+\frac{1}{2} \sigma_{b}^{2} c_{b}
$$

If the parties are risk averse $\left(c_{a}<0, c_{b}<0\right)$ then $y_{a s}<y_{a F}$ and $z_{b s}<z_{b F}$. Intuitively, the parties would be willing to settle with certainty for less than the expected arbitration award. This sacrifice is essentially a payment to avoid the disutility of the risk of arbitration. Alternatively, if the parties are risk lovers $\left(c_{a}>0, c_{b}>0\right)$ then $y_{a s}>y_{a F}$ and $z_{b s}>z_{b F}$ and the parties must be paid a premium in order to be discouraged from "enjoying" the risk of the arbitration process.

Assuming that the parties are expected utility maximizers, party $a$ would prefer to negotiate any settlement $y_{a}>y_{a s}$ rather than resort to arbitration while party $b$ would prefer to negotiate any settlement $z_{b}>z_{b s}$ rather than resort to arbitration. In order to determine if there is a zone of potential agreement (a contract zone), note that if $z_{b s}$ is the minimum share for $b$ that will cause $b$ to prefer a negotiated settlement, then $1-z_{b s}=y_{b s}$ is the maximum share that $b$ would be willing to give $a$ and still prefer a negotiated settlement. From Equation 14

$$
y_{b s}=1-z_{b s}=1-z_{b F}-\frac{1}{2} \sigma_{b c}^{2} b
$$
and

$$
y_{b s}=y_{b F}-\frac{1}{2} \sigma_{b}^{2} c_{b}
$$

where $y_{b F}$ is party $b$ 's prior expectation of the arbitrator's decision of $a$ 's share.

Thus, $a$ will accept any negotiated settlement $\left(y_{n}\right)$ satisfying $y_{n}>y_{a s}$ and $b$ will accept any negotiated settlement satisfying $y_{n}<y_{b s}$. Thus, the contract zone or range of potential settlements is

$$
\begin{aligned}
\Delta=y_{b s} & -y_{a s}=y_{b F}-y_{a F}-\frac{1}{2}\left(\sigma_{a}^{2} c_{a}\right. \\
& \left.+\sigma_{b}^{2} c_{b}\right) .
\end{aligned}
$$

If $\Delta$ is less than or equal to zero, there is no contract zone and the arbitration procedure will be used. ${ }^{12}$ (The question of the point in any existing contract zone at which the parties actually negotiate a settlement will be discussed later.)

Examination of Equation 17 shows that the contract zone is defined by the risk preferences of the parties and the expectations of the parties concerning the arbitrator's behavior. In view of the fact that the contract zone sets the bounds for negotiated settlements, it is clear that the arbitrator's expected behavior directly affects negotiated settlements. We next investigate the role that risk preferences and expectations about the arbitrator's award play in determining the size of the contract zone and, hence, the frequency of use of the procedure.

\section{Frequency of Use}

It is clear from Equation 17 that the larger the difference between $y_{b F}$ and $y_{a F}$ is, the larger the contract zone will be. In other words, if the parties have relatively pessimistic expectations about the arbitrator's award, then there may be room for a negotiated settlement. On the other hand, if the parties have relatively optimistic expectations about the behavior of the arbitrator, then this will tend to discourage a negotiated settlement by reducing the contract zone.

\footnotetext{
${ }^{12}$ All problems of communication are abstracted from, and it is assumed that if there is a contract zone then the parties find it.
} 
While there is no reason to assume that the parties' expectations vary in any systematic fashion, it may be true that when a procedure is first introduced the parties have differing and inaccurate expectations about the arbitrator's behavior. If this difference is relatively pessimistic (optimistic), the procedure will be invoked less (more) frequently than it would be, given accurate expectations.

It is reasonable to believe that over time the parties learn about the arbitrator's behavior both through their own experience and, indirectly, through the experience of others. This learning will have two effects on the parties' prior distributions of the arbitrator's expected behavior. First, it is expected that the means of the prior distributions $\left(y_{a F}\right.$ and $\left.y_{b F}\right)$ will converge to a common value $\left(y_{F}\right)$. Second, the variance of the distributions $\left(\sigma_{a}^{2}\right.$ and $\sigma_{b}^{2}$ ) will converge to a common value $\left(\sigma^{2}\right)$ and fall as the parties form more accurate expectations of the arbitrator's behavior.

With the convergence of expectations in the long run, Equation 17-representing the size of the contract zone $(\Delta)$-can be rewritten as

$$
\Delta=-\frac{1}{2} \sigma^{2}\left[c_{a}+c_{b}\right] .
$$

Recall that $c_{a}<0$ and $c_{b}<0$ imply risk aversion on the part of $a$ and $b$ respectively. If both parties are risk averse then $c_{a}+c_{b}<0$, which implies that $\Delta>0$ and that there is a contract zone.

The weaker condition for the existence of a contract zone given identical expectations is that risk aversion dominates $\left(c_{a}+c_{b}<0\right)$. It is not necessary that both parties be risk averse but only that the party which is risk averse be averse to risk more than the extent to which the other party loves risk.

In the simple world described above, the parties have identical expectations and, consequently, the utilization decision is completely determined by the relative risk preferences. Although identical expectations may be rare, it is reasonable to conclude that the relative risk preferences of the parties are an important determinant of the size of any contract zone and that short-run differences in expectations concerning the arbitrator's decision serve to modify the po- tential contract zone implied by the relative risk preferences of the parties.

It was demonstrated above that the relative risk preferences of the parties are crucial to the ability of an arbitration procedure to create a contract zone. For the procedure to be effective in the long run, risk aversion must dominate; yet, we have no idea if it does or will. There is almost a total absence of empirical evidence concerning the risk preferences of the parties in a collective bargaining situation. It is often assumed by neoclassical economists that firms in the private sector are risk-neutral profit maximizers. On the other hand, a significant degree of risk aversion was found in a recent study of the preferences of union members. ${ }^{13}$ If these findings are representative, it seems reasonable to believe that risk aversion dominates in the private sector.

In the public sector-the primary locus of interest arbitration procedures-there is no generally accepted objective function for the employer, but some tentative notions on the relative risk preferences of unions and employers can be developed. First, there is reason to expect that union members in the public sector are at least as risk averse as those in the private sector. ${ }^{14}$ Second, the public sector union is likely to exhibit more risk aversion than the employer. One reason for this is the fact that wages are the primary source of income of union members, and the penalties for losing the members' primary income source are liable to be severe. On the other hand wages are not the only expense of the government unit and the taxes that finance wages account for only a small share of the expenses of the citizenry.

In the context of the model developed earlier, it is likely that the union (party $a$ ) is risk averse $\left(c_{a}<0\right)$ and the public sector employer is less risk averse $\left(c_{b}>c_{a}\right)$. While it seems that the usual situation will be one of risk aversion dominating $\left(c_{a}+c_{b}<0\right)$, there is no convincing evidence of this. Risk-

\footnotetext{
${ }^{13}$ Henry S. Farber, "Individual Preferences and Union Wage Determination: The Case of the United Mine Workers," Journal of Political Economy, Vol. 86, No. 6 (October 1978), pp. 923- 42.

${ }^{14}$ It can be argued that public sector jobs are more secure and therefore attract more risk-averse individuals.
} 
loving behavior by the employer (or, however implausible, by the union) may imply dominance of risk-loving behavior $\left(c_{a}+c_{b}\right.$ $>0)$. With identical expectations about arbitrator behavior, this situation implies no contract zone, resulting in the parties' complete reliance on the procedure or a total "chilling" of bargaining.

Implicit in the preceding discussion is the assumption that some uncertainty persists in the long run $\left(\sigma^{2}>0\right)$. Although experience with the arbitration procedure will reduce the uncertainty, changing economic conditions and differences among arbitrators will probably negate the possibility that the parties can ever predict arbitrators' awards with certainty. If, however, all uncertainty were removed $\left(\sigma^{2}=0\right)$, then it is clear from Equation 18 that the contract zone would disappear. The parties would have no incentive to negotiate any settlement different from what the arbitrator would award. In this situation any discussion of the utilization rate of the arbitration procedure is moot because negotiated and arbitrated settlements would be identical. However, the shrinkage of the contract zone as the uncertainty disappears has the important implication that it reduces the ability of the parties to consider factors of which they alone are aware and which they can evaluate in reaching a negotiated settlement.

It has been argued that conventional arbitration "chills bargaining" because the parties have little or no uncertainty about the arbitrators' behavior. ${ }^{15}$ Final-offer arbitration has been suggested as an alternative to conventional arbitration that is "well designed to ... [ [generate] just the kind of uncertainty about the location of the arbitration award that is well calculated to ... compel [the parties] to seek security in agreement."16 Thus, final-offer arbitration was

\footnotetext{
${ }^{15}$ The so-called chilling effect of arbitration is discussed by Peter Feuille, "Final Offer Arbitration and the Chilling Effect," Industrial Relations, Vol. 14, No. 3 (October 1975), pp. $302-10$ and Harry H. Wellington and Ralph $\mathrm{K}$. Winter, Jr., The Unions and the Cities (Washington, D.C.: The Brookings Institution, 1971).

${ }^{16} \mathrm{Carl}$ M. Stevens, "Is Compulsory Arbitration Compatible with Bargaining?' Industrial Relations, Vol. 5, No. 1 (February 1966), pp. 38- 52.
}

conceived as a technique for increasing the uncertainty about the arbitrator's decision. Unless risk aversion dominates, however, an increase in uncertainty will not increase the size of the contract zone. This can be demonstrated by differentiating Equation 18 with respect to $\sigma^{2}$ as follows:

$$
\frac{\partial \Delta}{\partial \sigma^{2}}=-\frac{1}{2}\left(c_{a}+c_{b}\right)
$$

which is greater than (or less than) zero as risk aversion (or risk loving) dominates. Additionally, even if risk aversion dominates, it is not at all clear that a final-offer procedure involves more uncertainty than a conventional arbitration procedure, because the parties themselves have control over the final offers and hence can influence the probabilities of their award being chosen. ${ }^{17}$

The other criterion, discussed earlier, for evaluating the impact of a change in the arbitration procedure is the extent to which the introduction of a new procedure changes the terms of the settlement both in situations in which the procedure is used and those in which it is not. In order to investigate this problem, we now develop a simple bargaining theory of the determination of the negotiated settlement.

\section{Impact on Negotiated Settlements}

Let us assume that the relative bargaining power of the parties are such that a certain proportion $(\Phi)$ of the contract zone is always captured by party $a$ and that this is true regardless of the size or location of the contract zone. ${ }^{18}$ Since the certainty equivalent

\footnotetext{
${ }^{17}$ This discussion of final-offer arbitration is sug. gestive but not complete. Analysis of final-offer schemes is complicated by the endogeneity of the final offers. A model specific to the final-offer case is developed by Henry S. Farber, "An Analysis and Evaluation of Final Offer Arbitration," working paper no. 242, Department of Economics, M.I.T., 1979.

${ }^{18}$ The parameter $\Phi$ measures the aspect of bargaining power that determines the share of a given contract zone captured by each party. This is distinguished from those aspects of bargaining power that determine the location of the contract zone. The latter is largely a function of the relative costs of disagreement (relative risk preferences in this model), while the former is largely a function of relative bargaining skills. However, to the extent that $\Phi$ is also a function of relative risk preferences, this analysis becomes more complicated.
} 
share of party $a\left(y_{a s}\right)$ is the lower bound of any positive contract zone, the actual negotiated settlement under the simple bargaining power model is

$$
y_{n}=y_{a s}+\Phi \Delta
$$

where $0 \leqq \Phi \leqq 1$. Of course, this only applies where $\Delta^{\prime}$ is greater than zero. If $\Delta$ is less than zero then there is no contract zone and arbitration is invoked.

Maintaining the assumption of identical and accurate expectations about the arbitrator's behavior and substituting from Equations 13 and 18 into Equation 20 for $y_{a s}$ and $\Delta$ yields ${ }^{19}$

$$
\begin{aligned}
& y_{n}=y_{F}+\frac{1}{2} \sigma^{2} c_{a}-\Phi \frac{1}{2} \sigma^{2}\left(c_{a}+c_{b}\right) \text { or } \\
& y_{n}=y_{F}+\frac{1}{2} \sigma^{2}\left[(1-\Phi) c_{a}-\Phi c_{b}\right] .
\end{aligned}
$$

If party $a$ has all of the bargaining power $(\Phi=1)$, then $y_{n}=y_{F}-\frac{1}{2} \sigma^{2} c_{b}$, which is simply party $b$ 's certainty equivalent maximum share $\left(y_{b s}\right)$ for party $a .^{20}$ Alternatively, if party $b$ has all of the bargaining power $(\Phi=0)$, then $y_{n}=y_{F}+\frac{1}{2} \sigma^{2} c_{a}$, which is simply party $a$ 's certainty equivalent minimum share $\left(y_{a s}\right)$. In general $\Phi$ will not take on either of these extreme values but will lie somewhere between zero and one.

It is clear from Equation 22 that the expectation of the arbitrator's award $\left(y_{F}\right)$ is a major determinant of the negotiated settlement. Any change in $y_{F}$ will be passed through on a one-for-one basis $\left(\frac{\partial y_{n}}{\partial y_{F}}=1\right)$ to the negotiated settlement. In fact, as discussed previously, when the parties can predict the arbitrator's award with certainty $\left(\sigma^{2}=0\right)$, the negotiated settlement is exactly the predicted arbitrator's award.

The general approach used by others in evaluation of arbitration schemes is to compare negotiated with arbitrated settle-

\footnotetext{
${ }^{19}$ Accurate expectations are defined as the case in which the mean and variance of the prior distribution of the arbitrator's award are in fact the parameters of the actual distribution. This does not imply that the parties know the arbitrator's award with certainty.

20 See Equation 16.
}

ments. ${ }^{21}$ Any deviation is presumed to be evidence of a bias on the part of the arbitrator. However, it follows from Equation 22 that

$$
y_{n}-y_{F}=\frac{1}{2} \sigma^{2}\left[(1-\Phi) c_{a}-\Phi c_{b}\right] \text {. }
$$

Thus, the difference between negotiated and arbitrated settlements is not a function of the expected arbitrator's award $\left(y_{F}\right)$. Rather, it is a function of the uncertainty regarding the arbitrator's award $\left(\sigma^{2}\right)$, the relative bargaining power of the parties $(\Phi)$, and the relative risk preferences of the parties $\left(c_{a}\right.$ and $\left.c_{b}\right)$. Any change in the average arbitrator's award $\left(y_{F}\right)$ will change the negotiated outcomes by the same amount and, consequently, will not be detected by a simple comparison of negotiated and arbitrated outcomes.

A change in the uncertainty about the arbitrator's award $\left(\sigma^{2}\right)$ can also affect the location of the negotiated outcomes. Differentiation of $y_{n}$ in Equation 22 with respect to $\sigma^{2}$ yields

$$
\frac{\partial y_{n}}{\partial \sigma^{2}}=\frac{1}{2}\left[(1-\Phi) c_{a}-\Phi c_{b}\right] \text {. }
$$

The sign of this expression is indeterminant and depends on the relative risk preferences as well as the relative bargaining powers of the parties. Given that risk aversion dominates $\left(\left(c_{a}+c_{b}\right)<0\right)$, the necessary and sufficient condition for an increase in uncertainty to increase $y_{n}$

$$
\begin{aligned}
\left(\frac{\partial y_{n}}{\partial \sigma^{2}}>0\right) \text { is that } & \\
& \Phi>\frac{c_{a}}{c_{a}+c_{b}} .
\end{aligned}
$$

${ }^{21}$ Among others, see David B. Lipsky and John E. Drotning, "The Relation Between Teacher Salaries and the Use of Impasse Procedures Under New York's Taylor Law: 1968-1972," Journal of Collective Negotiations in the Public Sector, Vol. 6, No. 3 (1977), pp. 229-44; James L. Stern, Charles M. Rehmus, J. Joseph Loewenberg, Hirschel Kasper, and Barbara D. Dennis, Final-Offer Arbitration (Lexington, Mass.: D.C. Heath, 1975); and Mark Thompson and James Cairnie, "Compulsory Arbitration: The Case of British Columbia Teachers," Industrial and Labor Relations Review, Vol. 27, No. 1 (October 1973), pp. 3-17. 
While $\Phi$ measures the relative bargaining power of party $a, \frac{c_{a}}{c_{a}+c_{b}}$ measures the risk aversion of party $a$ relative to the total risk aversion of the two parties. Intuitively, Equation 25 has the implication that the share of party $a$ will increase with an increase in the uncertainty inherent in the procedure if the relative bargaining power of party $a$ is high enough to offset party $a$ 's risk aversion.

The most important conclusion that can be drawn from this portion of the analysis is that an increase in the uncertainty surrounding the arbitrator's award will bias the outcomes of negotiated settlements $\left(\frac{\partial y_{n}}{\partial \sigma^{2}} \neq 0\right)$

unless Equation 25 holds with equality, i.e.,

$$
\Phi=\frac{c_{a}}{c_{a}+c_{b}}
$$

There is no reason why this should be true, and it will only be the merest coincidence if, in fact, it is. Thus, it can be concluded that in general any change in the arbitration procedure that increases the uncertainty will bias the outcomes of negotiated settlements. The direction of the bias depends on the relationship between the bargaining power and the relative risk preferences of the parties.

Previous discussion suggested that there are reasons to expect that in the public sector, the union is likely to be more risk averse than the employer. Assume for expository purposes that the union is in fact "twice" as risk averse as the employer and that party $a$ is the union. In other words, $c_{a}=2 c_{b}<0$. Substitution into Equation 26 yields the result that the bargaining power of the union must be such that it captures exactly two-thirds of the contract zone $\left(\Phi=\frac{2}{3}\right)$ in order that a change in the uncertainty inherent in the procedure not bias the outcomes of negotiated settlements. If $\Phi>\frac{2}{3}$ then $\frac{\partial y_{n}}{\partial \sigma^{2}}>0$ and the union will gain from the increase in uncertainty. Obviously, if the bargaining powers are equal $\left(\Phi=\frac{1}{2}\right)$, then the union will lose because it is the more risk averse. $^{22}$

Consider the case in which the employer is risk neutral $\left(c_{b}=0\right)$. Substitution into Equation 25 implies that the union can never gain from a riskier procedure. In fact, in order to maintain its position, the union's bargaining power must be such that it captures the entire contract zone $(\Phi=1)$. In this polar case it is unlikely that the union will have such power, and as a result it will suffer from a change to a procedure that involves more uncertainty.

To summarize, the change to an arbitration procedure that involves more uncertainty will increase the size of the contract zone only as long as risk aversion dominates. This implies a higher probability of achieving a negotiated settlement. However, unless by chance the relative difference in risk preferences between the parties is exactly offset by differences in the bargaining power of the parties the outcomes of negotiated settlements will be biased by the change in the procedure.

\section{Summary and Implications}

In this study a model of the use of arbitration procedures and the outcomes of negotiated settlements in the presence of arbitration procedures was developed. The major implication of the analysis is that the presence of any arbitration procedure determines the environment within which the parties negotiate, and consequently, directly affects the terms of negotiated agreements.

This result has an important implication for the evaluation of arbitration (or any other mechanism) as a dispute settlement procedure. Introduction of a new dispute settlement procedure or any modification of an existing procedure will have an effect on negotiated agreements, and it is just this effect that makes assessment of any change in the dispute settlement mechanism difficult. Simple comparisons of negotiated settlements with arbitrated awards will be misleading because they ignore the effect of the

\footnotetext{
${ }^{22}$ If the parties have equal bargaining power, they must be equally risk averse for a change in uncertainty not to affect negotiated outcomes. The converse is also true.
} 
procedure on negotiations. ${ }^{23}$ In the context of the simple model developed here, it was demonstrated that a shift in the average arbitration award would shift the average negotiated settlement by the same amount. The measured difference between arbitrated and negotiated outcomes would be unchanged. Hence, this difference cannot be used as a measure of bias in the arbitration procedure.

The difference between arbitrated and negotiated settlements, while not a function of the average arbitrated award, was found to be related to the relative risk preferences and bargaining power of the parties as well as to the uncertainty regarding the arbitrator's behavior. The ability of an arbitration procedure to induce the parties to reach a negotiated settlement is due to the costs resulting from the uncertainty associated with the arbitrator's behavior. Thus, negotiated settlements will be less favorable to the party who is more risk averse. This effect must be considered when implementing any procedure that relies on uncertainty to encourage bargaining.

It was found that uncertainty about the arbitration award will create a range of potential negotiated settlements only if risk aversion dominates. While it seems likely

\footnotetext{
${ }^{23}$ Additionally, note that because of initial differences in expectations about the behavior of the arbitrators and because it may take time to learn about the behavior of the arbitrators, studies that attempt to measure the long-run impact of changes in procedures shortly after they are instituted are bound to be misleading.
}

that risk aversion does dominate, serious empirical investigation of the relative risk preferences of the parties would be useful.

It is likely that as the parties become familiar with arbitrators and the arbitration procedure, the uncertainty surrounding the procedure will be reduced. This may result in increased usage of the procedure as the contract zone shrinks. However, the more important effect is that all settlements (negotiated and arbitrated) will tend to converge as the uncertainty is reduced. This raises serious questions concerning the role of factfinding and the use of arbitration as an extension of the negotiating process. To the degree that arbitrators rely on the results of factfinding in making their awards, factfinding provides information to the parties concerning the arbitrator's behavior. This reduces the uncertainty inherent in the arbitration procedure and constrains the range of negotiated outcomes.

The direct exchange of information between the arbitrator and the parties will similarly reduce the uncertainty concerning the arbitrator's behavior. Any negotiated agreements reached after such an exchange of information are likely to reflect very closely the potential arbitrator's award. These considerations suggest that, in order to preserve the uncertainty surrounding the arbitration process and to encourage real bargaining, allowing the arbitrator to act as a mediator and other mechanisms that provide flows of information from the arbitrator to the parties will be counterproductive. 
Copyright of Industrial \& Labor Relations Review is the property of Cornell University and its content may not be copied or emailed to multiple sites or posted to a listserv without the copyright holder's express written permission. However, users may print, download, or email articles for individual use. 